\title{
Unidirectional endobronchial valves for management of persistent air-leaks: results of a multicenter study
}

\author{
Alfonso Fiorelli ${ }^{1}$, Antonio D'Andrilli ${ }^{2}$, Roberto Cascone ${ }^{1}$, Luisa Occhiati ${ }^{1}$, Marco Anile ${ }^{3}$, Daniele Diso ${ }^{3}$, \\ Francesco Cassiano ${ }^{2}$, Camilla Poggi ${ }^{2}$, Mohsen Ibrahim ${ }^{2}$, Giacomo Cusumano ${ }^{4}$, Alberto Terminella ${ }^{4}$, \\ Giuseppe Failla ${ }^{5}$, Alba La Sala ${ }^{5}$, Michela Bezzi ${ }^{6}$, Margherita Innocenti ${ }^{6}$, Elena Torricelli ${ }^{6}$, Federico \\ Venuta $^{3}$, Erino Angelo Rendina ${ }^{2}$, Giovanni Vicidomini ${ }^{1}$, Mario Santini ${ }^{1}$, Claudio Andreetti ${ }^{2}$ \\ ${ }^{1}$ Thoracic Surgery Unit, Università della Campania “Luigi Vanvitelli”, Naples, Italy; ${ }^{2}$ Thoracic Surgery Unit, Università La Sapienza, Sant'Andrea \\ Hospital, Rome, Italy; ${ }^{3}$ Thoracic Surgery Unit, Università La Sapienza, Policlinico Hospital, Rome, Italy; ${ }^{4}$ Thoracic Surgery Unit, Policlinico \\ Vittorio Emanuele Hospital, Catania, Italy; ${ }^{5}$ Interventional Pneumology Unit, Ospedale Civico Palermo, Palermo, Italy; ${ }^{6}$ Interventional Pneumology \\ Unit, Policlinico Firenze, Florence, Italy \\ Contributions: (I) Conception and design: A Fiorelli, A D'Andrilli, M Bezzi, C Andreetti, M Anile, G Cusumano, G Failla; (II) Administrative support: \\ E Torricelli; (III) Provision of study materials or patients: R Cascone, L Occhiati, D Diso, F Cassiano, C Poggi, M Ibrahim, A Terminella; (IV) \\ Collection and assembly of data: A La Sala, M Bezzi, M Innocenti, E Torricelli, G Vicidomini; (V) Data analysis and interpretation: A Fiorelli, A \\ D’Andrilli, M Bezzi, C Andreetti, M Anile, G Cusumano, G Failla; (VI) Manuscript writing: All authors; (VII) Final approval of manuscript: All \\ authors. \\ Correspondence to: Alfonso Fiorelli, MD, PhD. Thoracic Surgery Unit, Università degli Studi della Campania "Luigi Vanvitelli”, Piazza Miraglia, 2, \\ I-80138 Naples, Italy. Email: alfonso.fiorelli@unicampania.it.
}

Background: To evaluate the efficacy of Endo-Bronchial Valves in the management of persistent air-leaks (PALs) and the procedural cost.

Methods: It was a retrospective multicenter study including consecutive patients with PALs for alveolar pleural fistula (APF) undergoing valve treatment. We assessed the efficacy and the cost of the procedure.

Results: Seventy-four patients with persistent air leaks due to various etiologies were included in the analysis. In all cases the air leaks were severe and refractory to standard treatments. Sixty-seven (91\%) patients underwent valve treatment obtaining a complete resolution of air-leaks in 59 (88\%) patients; a reduction of air-leaks in $6(9 \%)$; and no benefits in $2(3 \%)$. The comparison of data before and after valve treatment showed a significant reduction of air-leak duration $(16.2 \pm 8.8$ versus $5.0 \pm 1.7$ days; $\mathrm{P}<0.0001)$; chest tube removal $(16.2 \pm 8.8$ versus $7.3 \pm 2.7$ days; $\mathrm{P}<0.0001)$; and length of hospital stay (LOS) $(16.2 \pm 8.8$ versus $9.7 \pm 2.8$ days; $\mathrm{P}=0.004)$. Seven patients not undergoing valve treatment underwent pneumo-peritoneum with pleurodesis $(n=6)$ or only pleurodesis $(n=1)$. In only $1(14 \%)$ patient, the chest drainage was removed 23 days later while the remaining $6(86 \%)$ were discharged with a domiciliary chest drainage removed after $157 \pm 41$ days. No significant difference was found in health cost before and after endobronchial valve (EBV) implant $(\mathrm{P}=0.3)$.

Conclusions: Valve treatment for persistent air leaks is an effective procedure. The reduction of hospitalization costs related to early resolution of air-leaks could overcome the procedural cost.

Keywords: Zephyr endobronchial valves (Zephyr EBV); persistent air-leak (PAL); bronchoscopy; alveolar-pleural fistula

Submitted Jun 17, 2018. Accepted for publication Sep 132018.

doi: $10.21037 /$ jtd.2018.10.61

View this article at: http://dx.doi.org/10.21037/jtd.2018.10.61 


\section{Introduction}

Persistent air-leak (PAL) is a clinical condition that is due to an abnormal communication between the pulmonary parenchyma and pleural space that persisted for more than 5 to 7 days, despite constant drainage of thoracic cavity (1). PALs present secondary to various etiologies and treatment can be a challenge due to the poor healing ability of diseased lung. Surgery with direct repair of the alveolar pleural fistula (APF) remains the treatment of choice but most patients are not surgical candidates due to poor general clinical condition. In 2001 an American College of Chest Physicians (ACCP) consensus statement did not recommend bronchoscopy for the treatment of PAL $(1,2)$. However, in the last two decades encouraging results have been reported in small case series $(3-12)$ and review articles $(13,14)$ by the use of bronchial valves, originally designed for management of emphysema. There are currently 2 commercially available types of bronchial valves; the Zephyr endobronchial valve (EBV) (Zephyr, Pulmonx Corporation-Redwood City, CA, USA) and Spiration intra bronchial valves (IBV) (Olympus Respiratory America-Redmond, WA, USA). In the United States only the IBV has been approved for humanitarian use by the Food and Drug Administration (FDA) for treating air-leaks while in Europe the EBV has been approved for the management of emphysema and air-leaks. The valves differ in shape but have a similar mechanism that consists in preventing air entry during inspiration while allowing expiratory airflow and drainage of secretions. It limits the air-leaks and favors the healing of APF. However, the lack of a standard protocol, and its high cost, remain the main drawbacks to allow it to be widely used in this procedure setting.

Thus, the aim of the present study was to evaluate in a large series of patients the efficacy of EBV in the management of PALs and the cost of the procedure.

\section{Methods}

\section{Study design}

This was a multicenter, retrospective study that included 6, high-volume Italian centers with relevant experience of the EBV procedure. Each participating center has treated more than 10 patients. The data of all consecutive patients with PALs observed from January 2011 to October 2016 were retrospectively reviewed. Inclusion criteria were: (I) patients with air-leaks due to APF that persisted for more than 5 days and were refractory to conventional treatments; (II) patients unfit or at high risk for surgery; and (III) PALs that could not be controlled by a domiciliary pleural drainage system. Exclusion criteria were: (I) patients with PALs due to broncho-pleural fistula; and (II) patients with incomplete medical record and follow-up. Decisions regarding (I) the timing of EBVs implant and removal; (II) chest tube management; (III) performing additional procedures in case of EBV failure; and (IV) discharge planning were not standardized but directed by each participant center according to personal experience.

The end-points were: (I) to assess the efficacy of EBV treatment in air-leaks resolution and on allowing chest drainage removal; and (II) to evaluate the cost of the EBV procedure.

All patients were treated with Zephyr EBV (Zephyr, Pulmonx Corporation-Redwood City, CA, USA). In Europe, CE Mark cleared the use of EBVs for the treatment of emphysematous patients, and for damaged lung resulting in air-leaks (3-14). Thus, no specific approval by Institutional Review Board (IRB) was needed. Each patient signed a written informed consent for the treatment, and was aware of the pros and cons of procedure. The data, collected by each participating center, were retrospectively analyzed. The study design was approved by the Ethics Committee of University of Campania "Luigi Vanvitelli", coordinating center of the study (Ethical approval number: 833.18).

\section{Study population}

The following data were reviewed for each patient: demographics; co-morbidities; etiology of PAL [postoperative, primary spontaneous pneumothorax (PSP), secondary spontaneous pneumothorax (SSP), and iatrogenic]; number and size of valves placed; time from chest tube placement to valve insertion (days); time from valve insertion to chest tube removal (days); length of hospital stay (LOS) (days) before and after valve deployment; additional interventions in case of EBV failure to control air-leaks; time of valve removal (days); and morbidity, and mortality related to the procedure. Air-leaks were assessed daily along the water compartment of the drainage system and classified according to the Cerfolio's classification (15) as following: grade 1 (forced expiratory only); grade 2 (expiratory only); grade 3 (inspiratory only); grade 4 (continuous). Chest-X ray and/or computed tomography scan (according to the preference of each treating center) were used to follow-up the target lung reexpansion after valve implant. When the air-leak stopped 


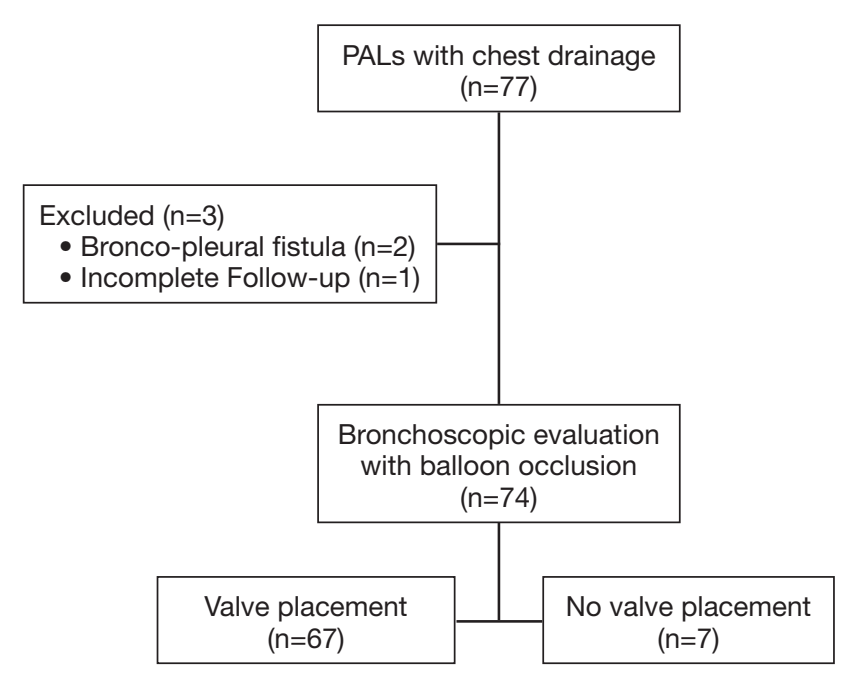

Figure 1 Flow chart of the study.

following EBV placement, the chest tube was clamped for 12-24 hours and then removed, as indicated. Patients with PALs also after EBV treatment underwent additional treatments that were left to the treating physician. All patients were followed-up at 3-6 months for optional valve removal.

\section{Procedure of valve implant}

The type of anesthesia used during the procedure varied across the centers, depending on patient condition, and physician preference. Generally, the procedure was performed with IV sedation, spontaneous breathing, and flexible bronchoscopy. Alternatively, general anesthesia with either a laryngeal mask or endotracheal tube to provide positive airway pressure was used. To identify the source of air-leaks, a Fogarty Catheter was inserted into the lobar bronchus suspected of supplying the airleak. The catheter balloon was inflated, and the air leak rate was assessed through the chest tube 5 minutes later. If the air leak reduced, the procedure was repeated in each individual segment to identify the exact source of air-leak. If more than one segment was identified with an air-leak, the primary segment that supplied it was treated first; and if the air leak resolved, the remaining segments were not treated. Patients with PALs after balloon-occlusion technique were excluded from EBV treatment. Two different sizes of valves were used: EBV 4.0 and EBV 5.5 for bronchial lumens with diameters of 4.0-7.0 mm, and of 5.5-8.5 mm, respectively.
After measuring the size of the target bronchus, the valve was delivered with the Zephyr Delivery Catheter while a continuous visual evaluation of the air-leak chamber assessed leak reduction.

\section{Cost analysis}

The mean cost per patient was calculated based on daily hospital cost ( $€ 650,00)$, pharmacy charges ( $€ 700$ per day and $€ 1,700$ per day in presence of complications such as pneumonia); the valves cost ( $€ 3.500$ for the smaller EBV 4.0 valve and $€ 5.500$ for the larger EBV 5.5 valve); the cost of the valve delivery catheter $(€ 40,000)$; cost of Fogarty Catheter $(€ 1,500)$; and the cost of operating room and its staff (€2,000 per minute).

\section{Statistical analysis}

We used the Kolmogorov-Smirnov test and graphic histograms to check the normality/skewness of continuous variables, and appropriate statistical tests have been chosen accordingly. Data were summarized as mean and standard deviation (SD) for continuous variables or absolute number and percentage for categorical variables. Fisher's exact test and Student $t$-test was used to compare categorical variables and continuous variables, respectively. Multiple comparison was made using ANOVA test. A P value $<0.05$ was considered significant. MedCalc statistical software (Version 12.3, Broekstraat 52; 9030 Mariakerke; Belgium) was used for the analysis.

\section{Results}

Seventy-seven patients unfit or at increased risk for surgery presented PALs during the study period. Of these, three patients were excluded from the analysis since the PALs were due to a broncho-pleural fistula $(\mathrm{n}=2)$, and incomplete follow-up $(\mathrm{n}=1)$. Thus, 74 patients were included in the study (Figure 1). Of these, 67 (91\%) patients underwent EBV treatment while 7 (9\%) patients did not receive valve implant since the source of air leaks was not identified by balloon occlusion technique. Characteristics of the study population are summarized in Table 1 . The mean age was $64 \pm 17$ years. The etiology of air-leaks was postoperative $(n=42)$, SSP $(n=24)$; PSP $(n=2)$; and iatrogenic pneumothorax $(n=6)$. Iatrogenic pneumothorax occurred in 5 patients after a CT-guided fine-needle aspiration 
Table 1 Characteristics of study population

\begin{tabular}{|c|c|}
\hline Variables & Values \\
\hline Patients & 74 \\
\hline Male/female & $53 / 21$ \\
\hline Age (years) & $64 \pm 17$ \\
\hline Co-morbidity & $120^{*}$ \\
\hline COPD & $59(49 \%)$ \\
\hline Cancer & $36(30 \%)$ \\
\hline Infectious & $11(9 \%)$ \\
\hline Cardiovascular & $7(6 \%)$ \\
\hline Diabetes & $5(4 \%)$ \\
\hline Systemic rheumatic disease & $2(2 \%)$ \\
\hline Charlson comorbidity index score & $4.7 \pm 1.6$ \\
\hline Asa physical status & $2.6 \pm 0.7$ \\
\hline \multicolumn{2}{|l|}{ Causes of air-leaks } \\
\hline Post-operative & $42(57 \%)$ \\
\hline Lobectomy & $7(17 \%)$ \\
\hline Wedge resection & $8(19 \%)$ \\
\hline Sleeve lobectomy & $1(2 \%)$ \\
\hline Decortication & $13(31 \%)$ \\
\hline Bullectomy & $13(31 \%)$ \\
\hline Secondary spontaneous pneumothorax & $24(32 \%)$ \\
\hline Emphysematous bulla & $22(92 \%)$ \\
\hline Cavitary infection process & $2(8 \%)$ \\
\hline Primary spontaneous pneumothorax & $2(3 \%)$ \\
\hline Latrogenic & $6(8 \%)$ \\
\hline After FNAB & $5(83 \%)$ \\
\hline Malposition of nasogastric feeding tube & $1(17 \%)$ \\
\hline
\end{tabular}

*, the sum of the comorbidities is more than 67 since a patient could have more than one co-morbidity. COPD, chronic obstructive pulmonary disease; ASA, American Society of Anaesthesiologist; FNAB, fine-needle aspiration biopsy.

biopsy to diagnose a lung lesion, and after malposition of a nasogastric tube in one patient. All cases of spontaneous pneumothorax and post-operative PAL were in the settings of compromised lung function and/or poor clinical condition that contraindicated the surgical treatment or limited its probability of success.

\section{Air leaks characteristics and treatment}

\section{Patients undergoing EBV treatment $(n=67)$}

The data are summarized in Table 2. All but two patients presented severe air leaks (grade 4). Before valve insertion, no reduction of air leaks were observed in all cases, despite the use of suction and additional treatments such as autologous blood patch pleurodesis $(\mathrm{n}=8)$; talc pleurodesis $(\mathrm{n}=11)$; and pneumoperitoneum $(\mathrm{n}=6)$. The mean time from chest tube placement to EBV implant was $16.2 \pm 8.8$ days. Nineteen patients had air-leaks for $\geq 1$ week while 48 patients had air-leaks for $\geq 2$ weeks. Patients with airleaks due to iatrogenic pneumothorax were treated earlier compared to other subgroups $(\mathrm{P}=0.0067) ; 1.2 \pm 0.4$ valves were implanted per patient and most of the procedures (92\%) were performed with spontaneous breathing and moderate sedation. There were no complications or deaths during the procedures.

\section{Patients not undergoing EBV treatment $(n=7)$}

All patients presented severe air leaks (grade 4). Six/7 $(86 \%)$ patients presented post-operative PALs after decortication $(n=5)$ and after lobectomy $(n=1)$, and $1 / 7$ patient (14\%) presented SPP PALs due to emphysematous bulla. In addition to chest drainage suction, 6 patients $(86 \%)$ underwent pneumo-peritoneum with blood patch pleurodesis $(n=3)$ or talc pleurodesis $(n=3)$, while 1 patient $(14 \%)$ received only talc pleurodesis without pneumoperitoneum.

\section{Clinical outcomes}

\section{Patients undergoing EBV treatment $(n=67)$}

The data are summarized in Table 3. In 59 (88\%) patients a complete resolution of air-leaks was obtained $2.9 \pm 1.4$ days from valve implant. Six (9\%) patients presented a reduction of air-leaks (from grade 4 to grade 2) that resolved following application of pneumoperitoneum $(n=4)$ or blood patch $(n=2) 14.6 \pm 1.8$ days later. Two (3\%) patients had no reduction of air-leaks, and underwent surgery $(\mathrm{n}=1)$ or additional valve placement with blood patch $(n=1)$. The reduction in air leak allowed these two patients to be discharged with a domiciliary chest drainage that was removed 70 and 180 days later. The comparison of data before and after EBV implant showed significant reduction in air leak duration $(16.2 \pm 8.8$ versus $5.0 \pm 1.7$ days; $\mathrm{P}<0.0001)$; in chest tube removal $(16.2 \pm 8.8$ versus $7.3 \pm 2.7$ days; 
Table 2 Characteristics of air-leaks in patients undergoing endobronchial valve placement

\begin{tabular}{|c|c|c|c|c|c|c|}
\hline Variable & All & Post-surgery & $\begin{array}{c}\text { Primary spontaneous } \\
\text { pneumothorax }\end{array}$ & $\begin{array}{c}\text { Secondary spontaneous } \\
\text { pneumothorax }\end{array}$ & latrogenic & $P$ value \\
\hline Number & 67 & 36 & 2 & 23 & 6 & \\
\hline Grade 4 & 65 & 35 & 2 & 22 & 6 & 0.94 \\
\hline Grade 3 & 2 & 1 & 0 & 1 & 0 & - \\
\hline Valves per patient & $1.2 \pm 0.4$ & $1.2 \pm 0.6$ & $1.0 \pm 0.2$ & $1.3 \pm 0.5$ & $1.1 \pm 0.3$ & 0.087 \\
\hline Operative time (min) & $21 \pm 2.9$ & $21 \pm 2.4$ & $20 \pm 0.3$ & $21 \pm 3.9$ & $22 \pm 3.8$ & 0.68 \\
\hline \multicolumn{7}{|l|}{ Valves placement } \\
\hline $\mathrm{RML}$ & $3(8.9 \%)$ & $1(33 \%)$ & $1(33 \%)$ & - & $1(33 \%)$ & 0.004 \\
\hline RLL & $6(9 \%)$ & $3(50 \%)$ & - & $3(50 \%)$ & - & 0.22 \\
\hline LUL & 13 (19\%) & $7(54 \%)$ & - & $5(38 \%)$ & $1(8 \%)$ & 0.89 \\
\hline Culmen & $4(6 \%)$ & $2(50 \%)$ & - & $1(25 \%)$ & $1(25 \%)$ & 0.68 \\
\hline Lingula & $11(16 \%)$ & $6(55 \%)$ & - & $4(36 \%)$ & $1(9 \%)$ & 0.93 \\
\hline LLL & $6(9 \%)$ & 5 (83\%) & - & - & $1(17 \%)$ & 0.23 \\
\hline $\mathrm{RUL}+\mathrm{RML}$ & $1(1 \%)$ & - & - & $1(100 \%)$ & - & 0.26 \\
\hline \multicolumn{7}{|l|}{ Procedure } \\
\hline
\end{tabular}

RUL, right upper lobe; RML, right middle lobe; RLL, right lower lobe; LUL, left upper lobe; LLL, lower left lobe; RUL + RML, right upper lobe and right middle lobe $(n=1)$.

$\mathrm{P}<0.0001)$; and in $\operatorname{LOS}(16.2 \pm 8.8$ versus $9.7 \pm 2.8$ days; $\mathrm{P}=0.004)$.

\section{Patients not undergoing EBV treatment ( $\mathrm{n}=7$ )}

Three of seven (43\%) patients achieved a mild reduction of air-leaks (from grade 4 to grade 3). In only one (14\%) patient, the chest drainage was removed 23 days later. The remaining $6(86 \%)$ patients were discharged with a domiciliary chest drainage (mean LOS $47 \pm 13$ days).

\section{Follow-up}

\section{Patients undergoing EBV treatment $(n=67)$}

The mean follow-up time was $37.7 \pm 4.1$ months. No atelectasis of the affected lobe was observed. Only one patient presented with hemoptysis that resolved with valve removal. The valves were removed in 55/67 (82\%) patients after a mean time of $134 \pm 83$ days from the implant using flexible bronchoscopy under deep sedation $(n=46)$ or general anesthesia $(n=9)$. In all cases, the valves were removed during a single session. All the valves were intact at the time of removal without any damage, distortion, or missing part. No complications or recurrence of air-leaks were observed after valve removal. The remaining 12 patients refused to have the valves removed. The permanence of valves did not cause any complication.

\section{Patients not undergoing EBV treatment $(n=7)$}

In 4 of $6(67 \%)$ patients, the chest drainage was removed after a mean of $157 \pm 41$ days, while the other $2(33 \%)$ patients presented an empyema that required thoracoscopic decortication. 
Table 3 Outcomes after endobronchial valves treatment

\begin{tabular}{|c|c|c|c|c|c|c|}
\hline Variable & All & $\begin{array}{l}\text { Post- } \\
\text { operative }\end{array}$ & $\begin{array}{l}\text { Primary spontaneous } \\
\text { pneumothorax }\end{array}$ & $\begin{array}{l}\text { Secondary spontaneous } \\
\text { pneumothorax }\end{array}$ & latrogenic & P Value \\
\hline Number & 67 & 36 & 2 & 23 & 6 & \\
\hline \multicolumn{7}{|l|}{ Resolution of air-leaks } \\
\hline Complete & $59(88 \%)$ & $33(56 \%)$ & $2(3 \%)$ & $18(31 \%)$ & $6(10 \%)$ & 0.30 \\
\hline Persistence & $2(3 \%)$ & $1(50 \%)$ & - & $1(50 \%)$ & - & 0.94 \\
\hline $\begin{array}{l}\text { Additional treatments after valve } \\
\text { implant }\end{array}$ & $8(12 \%)$ & & & & & \\
\hline Additional valve + blood-patch & $1(12.5 \%)$ & - & - & $1(100 \%)$ & - & 0.58 \\
\hline $\begin{array}{l}\text { Time from valve placement to } \\
\text { chest drainage removal (days) }\end{array}$ & $7.3 \pm 2.7$ & $7.9 \pm 1.8$ & $3.5 \pm 0.7$ & $7.1 \pm 1.1$ & $4.1 \pm 0.4$ & 0.16 \\
\hline $\begin{array}{l}\text { Time from valve placement to } \\
\text { discharge (days) }\end{array}$ & $9.7 \pm 2.8$ & $9.9 \pm 2.3$ & $4.5 \pm 0.7$ & $8.4 \pm 2.1$ & $5.5 \pm 1.3$ & 0.17 \\
\hline
\end{tabular}

Table 4 Analysis of the cost (Euros)

\begin{tabular}{lccc}
\hline Variables & Before valve implant & After valve implant & P value \\
\hline Daily hospital stay & $10.283 \pm 5.104$ & $6.761 \pm 1.823$ & 0.035 \\
Pharmacy & $126 \pm 8.9$ & $81.3 \pm 19.6$ & 0.017 \\
EBV valves & - & $4.477 \pm 544$ \\
EBV catheter for implant & - & $441 \pm 123$ \\
Catheter for occlusion & - & 15 \\
Operative room charges & - & $354 \pm 121$ \\
Total health care & $10.411 \pm 5.159$ & $12.132 \pm 1.857$ \\
\hline
\end{tabular}

\section{Cost analysis}

The results are summarized in Table 4. The comparison of the cost before and after EBV implant showed a significant reduction of cost of hospital stay ( $€ 10.283 \pm 5.104$ versus $€ 6.761 \pm 1.823$; $\mathrm{P}=0.035)$; and the pharmacy costs $(€ 126 \pm 8.9$ versus $€ 81.3 \pm 19.6 ; \mathrm{P}=0.017)$ after valve treatment. No significant difference was found for the entire cost of hospitalization before (daily hospital + pharmacy charges) versus after EBV implant (daily hospital + pharmacy charges + valves + implant catheter + balloon catheter + operative room) with total costs of $€ 10.411 \pm 5.159$ versus $€ 12.132 \pm 1.857 ; \mathrm{P}=0.374$.

\section{Discussion}

The management of PAL is still a challenge. The encouraging results obtained with the use EBV for management of PAL are based on few sample reports, summarized in Table 5, but none of these reports evaluated the cost-effectiveness of this treatment that remains a crucial issue considering the valve costs. Due to the low incidence of PALs, in order to collect a large number of cases, we planned a multicenter study including all high volume Italian Centers. Consistent with previous protocols (3-11), EBVs were deployed after identification of the air- 


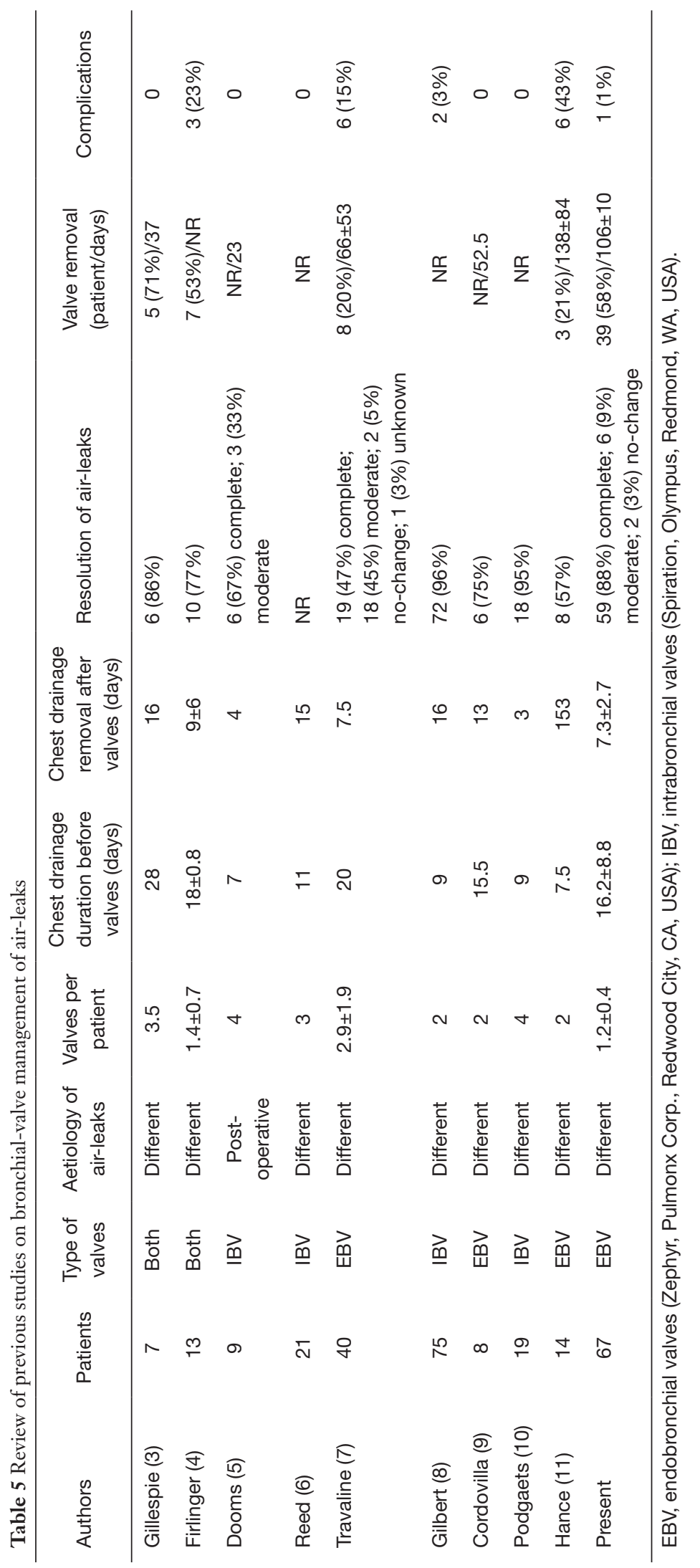


leaks source using the "balloon occlusion" method. We occluded only segmental bronchi supplying the source of air-leak, and avoided performing a complete lobar exclusion in patients undergoing previous lobectomy to preserve ventilation in limited residual areas of the lung. This strategy reduced the number of valves used compared to other studies $(3,5-11)$. Seven patients with unsuccessful bronchoscopic identification of air leak source were excluded from EBV treatment. Five of these underwent pleural decortication that theoretically affected bronchial segments of different lobes making it difficult to identify the source of the air leak.

The valves were deployed after a median time of 19 days from drain insertion, as in other reports (3-11). However, 19/67 (28\%) patients were treated with less than 2 weeks. Five patients presented iatrogenic air-leaks related to a trans-cutaneous needle biopsy for diagnosing advanced lung cancer. Thus, a fast resolution of PALs was required to prevent any delay in chemotherapy. Two patients with PSP underwent previous operations, and re-interventions for treating the recurrence were considered high-risk procedures. Twelve patients with SSP had a rupture of emphysematous bulla, and they were considered unfit for surgery due to severe comorbidities. In all cases, the air-leaks were severe (grade 4) and refractory to suction drainage, and to additional treatments such as autologous blood patch pleurodesis; talc pleurodesis; and pneumoperitoneum. Since there is a very low possibility of spontaneous resolution therefore supporting early EBV treatment is considered as the only strategy to resolve or reduce the amount of air leak. After EBV insertion, we observed a complete resolution of air-leaks in 59/67 (88\%) patients. Of these, $40 / 59$ (68\%) patients had complete resolution within 24 hours after valve placement, and $19 / 59$ (32\%) patients within 7 days without any significant difference related to the etiology of air leaks, in line with previous studies (3,4,6-11). In 6/67 (9\%) patients, EBV implant led to a significant reduction in the amount of air leak, and adjuvant treatments such as pneumo-peritoneum and autologous blood patch facilitated complete resolution.

In 2/67 (3\%) patients, EBV treatment failed to resolve the air leaks. The presence of collateral ventilation and the failure to occlude the target air-way could have been the main reason for persistence of air-leaks also after valve implant. The significant reduction of the time of chest tube removal, and of LOS confirmed the effect of the procedure for air leaks control. Our data are consistent with prior reports $(3,6-9)$ where the median time from valve placement to chest tube removal ranged from 8 to 16 days. Only Dooms et al. (5) reported a quicker removal of chest tube than the present report. We used a traditional chest drainage system with a subjective quantification of airleaks, while Dooms et al. (5) used a digital thoracic drainage system, with an objective and continuous monitoring of the air leak. Furthermore, Dooms et al. (5) restricted the indication of valve treatment to patients with "more localized" air-leaks since they included only PALs due to anatomical lung resection but excluded those caused by PSP, SPS or decortication, as in the present study. Thus, these differences could explain the different results compared to our study.

Consistent with other published series (3-11), the valves were removed in $65 \%$ of cases and left in place in the remaining $35 \%$ of patients without any problem. The safety of this strategy is supported by other studies, in which valves were placed permanently for emphysema or for prolonged periods for other medical conditions (13-17).

The cost of EBVs remains the main limitation for their large use (18-20). Due to the lack of a control group, to evaluate the valve cost we adopted a simple mathematical model considering several variables as the daily hospital cost before and after valve implant, and the cost of the valve procedure. We found that the total cost related to valve management was not significantly different than the health cost before valve implant. However, if we considered only the daily hospital stay cost, a significant reduction after valve implant was observed. Since PAL adds significantly to health care costs due to the prolonged LOS, in theory the reduction of LOS obtained with early EBV treatment likely demonstrates the cost effectiveness of this approach. Varela et al. (21) calculated that the total prolonged stay for patients with PAL after lobectomy $(\mathrm{n}=23)$ compared to control group $(\mathrm{n}=215)$ was 62 days; with an estimated total expense resulting from PAL of $€ 39,437.39$ ( $€ 38,724.96$ hospital stay and $€ 712.43$ pharmacy charges). To reduce the cost of hospitalization of PALs, a possible strategy is to discharge home patients with domiciliary chest drainage as supported by Cerfolio et al. (22). It was adopted in 6 of our patients who did not undergo EBV treatment, but this strategy was not free of expenses; the costs were shifted to primary or ambulatory care service as some of these patients lived in rural areas away from hospital. In addition, 2 patients developed pleural empyema that required thoracoscopic decortication. PALs patients are prone to developing major postoperative morbidity $(18,19,21,22)$. In the Varela's series (21), three out of 23 PAL patients 
discharged home with domiciliary chest drainage were readmitted due to pneumothorax, and or infection that could have been related to PAL.

\section{Study limitations}

Several limitations of our study did not allow us to draw definitive conclusions on the real efficacy of EBV for the treatment of PAL. (I) Due to the retrospective and multicenter nature of the study, the decision algorithm for placing EBV, the experience in valve placement, and the decision for planning additional interventions were different between the participating centers, and all these variables could have affected the final results. (II) Due to the lack of standardization in suction level and the subjective assessment of air leaks, the timing of chest-tube removal was established by the treating physicians rather than being guided by predefined criteria. In theory, some patients could have unnecessarily had the chest tube in place for more days resulting in an underestimation of the clinical benefits of valve implantation.

\section{Conclusions}

The use of EBV is a promising strategy for treatment of PAL. The reduction of LOS obtained with the early resolution of air-leaks could justify the costs of the procedure. For the success of the treatment, the exact identification of the source of the air leaks is mandatory to identify the patients who will benefit from this treatment, and to reduce the amount of lung parenchyma to (temporally) exclude, and the number of valves to implant. A prospective trial comparing valve placement versus standard of care is currently registered, and recruiting patients. The data from this and future prospective studies will help to define the real efficacy of this treatment.

\section{Acknowledgements}

This study was supported by the funding of "VALERE" research program from University of Campania Luigi Vanvitelli. The authors thank Eangelica Aton for editing English language.

\section{Footnote}

Conflicts of Interest: The authors have no conflicts of interest to declare.
Ethical Statement: The study was approved by the Ethics Committee of University of Campania "Luigi Vanvitelli" (No. 833.18) and written informed consent was obtained from all patients.

\section{References}

1. Mueller MR, Marzluf BA. The anticipation and management of air leaks and residual spaces post lung resection. J Thorac Dis 2014;6:271-84.

2. Wood DE, Cerfolio RJ, Gonzalez X, et al. Bronchoscopic management of prolonged air leak. Clin Chest Med 2010;31:127-33.

3. Gillespie CT, Sterman DH, Cerfolio RJ, et al. Endobronchial valve treatment for prolonged air leaks of the lung: a case series. Ann Thorac Surg 2011;91:270-3.

4. Firlinger I, Stubenberger E, Müller MR, et al. Endoscopic one-way valve implantation in patients with prolonged air leak and the use of digital air leak monitoring. Ann Thorac Surg 2013;95:1243-9.

5. Dooms CA, Decaluwe H, Yserbyt J, et al. Bronchial valve treatment for pulmonary air leak after anatomical lung resection for cancer. Eur Respir J 2014;43:1142-8.

6. Reed MF, Gilbert CR, Taylor MD, et al. Endobronchial Valves for Challenging Air Leaks. Ann Thorac Surg 2015;100:1181-6.

7. Travaline JM, McKenna RJ Jr, De Giacomo T, et al. Endobronchial Valve for Persistent Air Leak Group. Treatment of persistent pulmonary air leaks using endobronchial valves. Chest 2009;136:355-60.

8. Gilbert CR, Casal RF, Lee HJ, et al. Use of OneWay Intrabronchial Valves in Air Leak Management After Tube Thoracostomy Drainage. Ann Thorac Surg 2016;101:1891-6.

9. Cordovilla R, Torracchi AM, Novoa N, et al.

Endobronchial valves in the treatment of persistent air leak, an alternative to surgery. Arch Bronconeumol 2015;51:10-5.

10. Podgaetz E, Andrade RS, Zamora F, et al. Endobronchial Treatment of Bronchopleural Fistulas by Using Intrabronchial Valve System: A Case Series. Semin Thorac Cardiovasc Surg 2015;27:218-22.

11. Hance JM, Martin JT, Mullett TW. Endobronchial Valves in the Treatment of Persistent Air Leaks. Ann Thorac Surg 2015;100:1780-5.

12. Fiorelli A, Costanzo S, Carelli E, et al. Bronchoscopic treatment of complex persistent air leaks with endobronchial one-way valves. Gen Thorac Cardiovasc 
Surg 2016;64:234-8.

13. Mahajan AK, Khandhar SJ. Bronchoscopic valves for prolonged air leak: current status and technique. J Thorac Dis 2017;9:S110-5.

14. Lerner AD, Yarmus L, Gorden JA, et al. Intrabronchial valves for persistent air-leaks: what's the verdict? Expert Rev Respir Med 2016;3:1-3.

15. Cerfolio RJ, Tummala RP, Holman WL, et al. A prospective algorithm for the management of air leaks after pulmonary resection. Ann Thorac Surg. 1998;66:1726-31.

16. Fiorelli A, Accardo M, Vicidomini G, et al. Does cannabis smoking predispose to lung bulla formation? Asian Cardiovasc Thorac Ann 2014;22:65-71.

17. Santini M, Fiorelli A, Vicidomini G, et al. Endobronchial treatment of giant emphysematous bullae with one-way valves: a new approach for surgically unfit patients. Eur J

Cite this article as: Fiorelli A, D'Andrilli A, Cascone R, Occhiati L, Anile M, Diso D, Cassiano F, Poggi C, Ibrahim M, Cusumano G, Terminella A, Failla G, La Sala A, Bezzi M, Innocenti M, Torricelli E, Venuta F, Rendina EA, Vicidomini G, Santini M, Andreetti C. Unidirectional endobronchial valves for management of persistent air-leaks: results of a multicenter study. J Thorac Dis 2018;10(11):6158-6167. doi: 10.21037/ jtd.2018.10.61
Cardiothorac Surg 2011;40:1425-31.

18. Lackey A, Mitchell JD. The cost of air leak: physicians' and patients' perspectives. Thorac Surg Clin 2010;20:407-11.

19. Fann JI, Berry GJ, Burdon TA. The use of endobronchial valve device to eliminate air leak. Respir Med 2006;100:1402-6.

20. Fiorelli A, D'Andrilli A, Anile M, et al. Santini M. Sequential Bilateral Bronchoscopic Lung Volume Reduction With One-Way Valves for Heterogeneous Emphysema. Ann Thorac Surg 2016;102:287-94.

21. Varela G, Jimenez MF, Novoa N, et al. Estimating hospital costs attributable to prolonged air leak in pulmonary lobectomy. Eur J Cardiothorac Surg 2005;27:329-33.

22. Cerfolio RJ, Bass CS, Pask AH, et al. Predictors and treatment of persistent air leaks. Ann Thorac Surg 2002;73:1727-30. 